\title{
Pandemia y vacunas, ¿quimera o realidad?
}

\author{
SERGIO GEORGE ${ }^{1, \mathrm{a}}$, JUAN PABLO TORRES TORRETI ${ }^{2, \mathrm{a}, \mathrm{b}}$, \\ MIGUEL O'RYAN, MD ${ }^{3, a}$
}

\section{Pandemic and vaccines, chimera or reality?}

$\mathrm{E}$ 111 de marzo de 2020 la Organización Mundial de la Salud (OMS) declaró la infección por coronavirus SARS-CoV-2 como una pandemia, 3 meses después de los primeros casos de enfermedad respiratoria grave descritos en Wuhan, China. Estamos viviendo la mayor crisis sanitaria del siglo que a la fecha de escritura de esta editorial, reporta más de 4.500 .000 casos y más de 300.000 fallecidos a nivel mundial ${ }^{1}$. Las cifras reales son significativamente mayores, dado el subdiagnóstico de pacientes sintomáticos, y la desconocida prevalencia en pacientes con síntomas leves o asintomáticos.

La alta capacidad de transmisión persona a persona, a través de secreciones respiratorias, fómites, con un posible rol menor de la vía fecal-oral ${ }^{2}$, han llevado a un rápido y exponencial aumento de casos en todo el mundo, y al colapso del sistema de salud en varios países dada la sobredemanda de camas críticas. Esta es también, la amenaza creciente para nuestro país.

Se desconoce aún si el desarrollo de inmunidad humoral y/o celular post infección, detectada a partir de la semana de infección ${ }^{3}$, confiere protección a mediano-largo plazo. Los reportes de reinfecciones, al menos al corto plazo, son escasos, lo que aumenta la probabilidad de inducción de inmunidad protectora. Las proyecciones, aún con varias imperfecciones, sugieren que el tiempo requerido para lograr suficiente inmunidad de rebaño conferido por el curso de la infección natural, como para frenar la amenaza de nuevos brotes, demoraría varios años ${ }^{4}$ Lo anterior fundamenta la urgente necesidad de contar con una o más vacunas seguras y eficaces al más corto plazo posible. Sin embargo, este proceso no está exento de dificultades, pues requiere acelerar el desarrollo de vacunas, pero manteniendo los estándares de calidad para que éstas sean efectivas y seguras ${ }^{5}$.

La efectividad de una vacuna depende de su capacidad de inducir una respuesta inmune protectora, pero por otro lado, se debe asegurar que la vacuna no induzca una enfermedad más severa, fenómeno paradójico denominado "immune-enhancement", que ha sido observado en el desarrollo de vacunas para otros virus respiratorios y también en SARS-CoV- $1^{6}$, mediante 2 posibles mecanismos: uno dependiente de anticuerpos ${ }^{7}$, en que la presencia de anticuerpos inducidos por vacuna facilita la replicación viral en lugar de actuar como neutralizantes; y otro mecanismo celular, en que la inducción de una respuesta predominante Th2 acelera el daño tisular producido por la enfermedad ${ }^{4}$.

Considerar esta variable es de vital importancia en el caso de SARS-CoV-2, en que la desregulación de la respuesta inmune en forma de tormenta de citoquinas se ha asociado a los casos graves ${ }^{8}$. Por tanto, una adecuada selección de la tecnología para desarrollar la vacuna y el debido análisis preclínico son necesarios para obtener una respuesta inmune protectora y segura.

A la fecha, según datos de la OMS existen 110 vacunas para SARS-CoV-2 en estudio ${ }^{9}$, incluyendo vacunas a virus inactivado, virus atenuado, subunidades proteicas, vacunas de $\mathrm{ARN}, \mathrm{ADN}$, partículas similares a virus (VLPs) o virus recombinante no replicante. De éstas, ocho reportan al momento de este escrito el inicio de estudios clínicos en seres humanos. Las 2 primeras en iniciar estudios se encuentran actualmente en fase II: la primera desarrollada por Moderna (EE. UU.) en base a ARN mensajero codificante de la proteína de fusión "spike" necesaria para la entrada del virus 
a la célula, que inició estudios clínicos en paralelo a estudios preclínicos en animales en un esfuerzo por acelerar el proceso (NCT04283461); y la segunda desarrollada por CanSino Biologics (China) en base a la inserción de un segmento genético de coronavirus en el vector viral adenovirus humano 5 , modificado para transformarlo en un virus no replicante (NCT04313127). Investigadores de la Universidad de Oxford han avanzado, en forma acelerada, una estrategia similar (NCT04324606). Las potenciales ventajas de este candidato son que el vector es un adenovirus "simio" y por ende más distante antigénicamente a aquellos adenovirus que pueden infectar a seres humanos, como es el caso del adenovirus humano 5. Lo anterior hace menos probable que induzca una respuesta inmune contra el vector, impactando en su efectividad, como se ha descrito para el virus humano. Adicionalmente, la plataforma propuesta por Oxford, lleva varios años en ensayos previos para otras patologías (MERS, influenza, Zika, entre otros). Estos candidatos se basan en el concepto de inocular un segmento genético (ARN o ADN), el cual es internalizado en células humanas para producir proteínas virales, que a su vez, inducen la respuesta inmune específica. Otro grupo de vacunas se basa en el concepto más tradicional de virus inactivado; de este grupo hay tres candidatos en fase clínica I/II, de manufactura fundamentalmente china (ChiCTR2000031809; 32459; NCT04352608). El desarrollo de estas vacunas muy probablemente marcará un "record", con una o más vacunas disponibles en 12-18 meses.

El prometedor y esperado desarrollo de estas vacunas en el contexto global planteará una serie de interrogantes una vez aprobado su uso en humanos, como la duración de la inmunidad sistémica conferida, y la importancia de la inmunidad de mucosas en la protección contra la infección; e importantes desafíos como la necesidad de producción masiva y distribución, debiendo establecerse grupos prioritarios según la realidad del momento. La pandemia por influenza H1N1 dejó el triste recuerdo de la competencia por obtener vacunas, mostrando las desigualdades entre regiones, países y al interior de los países. Repetir tal escenario sería lamentable para la humanidad.

Sin duda el coronavirus SARS-CoV-2 nos confronta con nuestra vulnerabilidad ante agentes infecciosos con potencial pandémico. La probabilidad real de nuevas pandemias es creciente, lo que exige, ya sin demora, la adopción de estrategias de cooperación, transparencia, desarrollo y acción multidisciplinaria a nivel internacional y en nuestro país. El mundo post Covid-19 deberá haber aprendido la lección, el tiempo dirá si estuvimos a la altura.

\section{Referencias}

1. Worldometers.info. COVID-19 Coronavirus Pandemic. 2020. Disponible en: https://www.worldmeters. Info/ coronavirus. [Consultado el 15 de mayo de 2020].

2. Wang W, Xu Y, Gao R, Lu R, Han K, Wu G, Tan W. Detection of SARS-CoV-2 in Different Types of Clinical Specimens. JAMA. 2020 Mar 11:e203786. doi: 10.1001/ jama.2020.3786. Epub ahead of print.

3. Wölfel R, Corman VM, Guggemos W, Seilmaier M, Zange S, Müller MA, et al. Virological assessment of hospitalized patients with COVID-2019. Nature. 2020 Apr 1. doi: 10.1038/s41586-020-2196-x. Epub ahead of print.

4. Ferguson NM, Laydon D, Nedjati-Gilani G, Imai N, Ainslie K, Baguelin M, et al. Impact of nonpharmaceutical interventions (NPIs) to reduce COVID-19 mortality and healthcare demand. March 16, 2020. Disponible en: https://www.imperial.ac.uk/media/imperial-college/ medicine/sph/ide/gida-fellowships/Imperial-CollegeCOVID19-NPI-modelling-16-03-2020.pdf. [Consultado el 15 de mayo de 2020].

5. Lurie N, Saville M, Hatchett R, Halton J. Developing Covid-19 Vaccines at Pandemic Speed. N Engl J Med. 2020 Mar 30. doi: 10.1056/NEJMp2005630. Epub ahead of print.

6. Bolles M, Deming D, Long K, Agnihothram S, Whitmore A, Ferris $\mathrm{M}$, et al. A double-inactivated severe acute respiratory syndrome coronavirus vaccine provides incomplete protection in mice and induces increased eosinophilic proinflammatory pulmonary response upon challenge. J Virol. 2011; 85 (23): 12201-15. doi: 10.1128/JVI.06048-11.

7. Wang SF, Tseng SP, Yen CH, Yang JY, Tsao CH, Shen $\mathrm{CW}$, et al. Antibody-dependent SARS coronavirus infection is mediated by antibodies against spike proteins. Biochem Biophys Res Commun. 2014; 22; 451 (2): 20814. doi: 10.1016/j.bbrc.2014.07.090.

8. Huang C, Wang Y, Li X, Ren L, Zhao J, Hu Y, et al. Clinical features of patients infected with 2019 novel coronavirus in Wuhan, China. Lancet. 2020; 395 (10223): 497-506. doi: 10.1016/S0140-6736(20)30183-5.

9. World Health Organization. DRAFT landscape of COVID-19 candidate vaccines - 11 May 2020. Disponible en: https://www.who.int/who-documents-detail/ draft-landscape-of-covid-19-candidate-vaccines. [Consultado el 15 de mayo de 2020]. 